\title{
Performance Evaluation of Titanate Nanotubes and Nanoribbons Deposited by Electrophoresis in Photoelectrodes of Dye-Sensitized Solar Cells
}

\author{
Antonio Paulo Santos Souza ${ }^{a}{ }^{\circledR}$, Odair Pastor Ferreira ${ }^{b}{ }^{\circledR}$, Vanja Fontenele Nunes ${ }^{\circledR}$, Ana Fabíola \\ Almeida ${ }^{c}$, Francisco Marcone Lima ${ }^{c}$, Francisco Nivaldo Aguiar Freire ${ }^{c}$ \\ ${ }^{a}$ Departamento de Pós-Graduação em Engenharia e Ciências de Materiais, Universidade Federal do \\ Ceará, Fortaleza, CE, Brasil \\ ${ }^{b}$ Laboratório de Materiais Funcionais Avançados (LaMFA), Departamento de Física, Universidade \\ Federal do Ceará, P.O. Box 6030, 60455-900, Fortaleza, CE, Brasil \\ ${ }^{c}$ Laboratório em Filmes Finos em Energias Renováveis (LAFFER), Departamento de Engenharia \\ Mecânica, Universidade Federal do Ceará, Fortaleza, CE, Brasil
}

Received: February 11, 2018; Revised: April 01, 2018; Accepted: April 20, 2018

\begin{abstract}
Nanoparticles of $\mathrm{TiO}_{2}$ have been the main semiconductor applied in Dye-sensitized solar cells (DSSCs). In this work, titanate nanotubes (NaTiNT) and nanoribbons, were obtained by the hydrothermal method from $\mathrm{TiO}_{2}$ anatase. These materials were deposited on conductive substrate by electrophoresis, with and without thermal treatment, sensitized by ruthenium-based dye and used as work electrode. Exposing those photovoltaic devices to visible radiation, with films before thermal treatment, a short-circuit current density $\left(\mathrm{J}_{\mathrm{SC}}\right)$ of $0.0012 \mathrm{~mA} / \mathrm{cm}^{2}$ was observed for the cell with NaTiNT, a current density of $0.0398 \mathrm{~mA} / \mathrm{cm}^{2}$ for the cell with Nanoribbons, and a current density of 0.4028 $\mathrm{mA} / \mathrm{cm}^{2}$ for the cell with $\mathrm{TiO}_{2}$ as electrode. After thermal treatment, a short-circuit current density of $0.4269 \mathrm{~mA} / \mathrm{cm}^{2}$ was observed for the cell with NaTiNT, a current density of $0.0765 \mathrm{~mA} / \mathrm{cm}^{2}$ for the Nanoribbons cell, and, finally, a current density of $0.3310 \mathrm{~mA} / \mathrm{cm}^{2}$ for the cell with $\mathrm{TiO}_{2}$ as electrode. The new morphological, structural and optical characteristics of these nanoparticles may contribute for the development and research of new generation photovoltaic devices.
\end{abstract}

Keywords: Titanate nanotube, Nanoribbons, Sensitized solar cell, Electrophoresis.

\section{Introduction}

Recent research has shown the importance of synthesis of new materials for electrodes in dye-sensitized solar cells (DSSCs), to study the effects of this type of technology and to improve its efficiency. Several methods of synthesis of $\mathrm{TiO}_{2}$ nanostructures applied to DSSCs are being developed. Among these methods, there are: sol gel method ${ }^{1}$, anodic electrochemistry $^{2}$, hydrothermal treatment ${ }^{3,4}$ and templateassisted method ${ }^{5}$. Each preparation method has unique advantages and functional features. The titanate nanostructures prepared from hydrothermal synthesis methods have attracted considerable interest because it has many uses, including solar cells $^{6-11}$. Studies suggest that titanate nanotubes (TiNTs) is a solid material with chemical composition of $\mathrm{Na}_{2-\mathrm{x}} \mathrm{H}_{\mathrm{x}} \mathrm{Ti}_{3} \mathrm{O}_{7}$. $\mathrm{nH}_{2} \mathrm{O}(0 \leq \mathrm{x} \leq 2)^{6-10}$ and may present itself in the form of tubes, wires, rods and sheets. In the TiNTs, the transport of electrons can be facilitated through its organized structure, contributing to an increase in the efficiency of various devices ${ }^{4,6,8,10}$
For applications in DSSCs, it is crucial to maximize the specific surface area to achieve a maximum adsorption of dye in the work electrode and possibly increase the efficiency of the cell. For this, nanoparticulated forms of $\mathrm{TiO}_{2}$ are widely used $^{6-13}$. However, other nanosized geometries, in particular, nanotubes or nanoribbons, may allow a much higher control of the chemical or physical behavior. By diminishing dimensions to the nanoscale, not only the specific surface area increases significantly but also the electronic properties may change considerably ${ }^{13,14}$. These effects may also contribute to drastically improve the reaction/interaction between a device and the surrounding media, thereby making the system more effective (kinetics), or even allow for entirely novel reaction pathways ${ }^{14}$. However, titanate applications in photovoltaic cells are still in early stages, therefore, several aspects within the context of the cell manufacturing and its efficiency still need to be investigated in detail.

Therefore, in the present work, titanate $\left(\mathrm{Na}_{2} \mathrm{Ti}_{3} \mathrm{O}_{7} \cdot \mathrm{nH}_{2} \mathrm{O}\right)$ nanotubes and nanoribbons powders were prepared from hydrothermal synthesis methods in an alkaline medium 
$(\mathrm{NaOH})^{7,10}$. These materials and its precursor were supported in the form of films via electrophoresis, sensitized with $\mathrm{N} 719^{15}$, and used as part of DSSC cells. In addition, the samples were characterized by Scanning Electron Microscopy (SEM), Raman spectroscopy, X-Ray Diffraction (XRD) and Ultraviolet-Visible Spectroscopy (UV-VIS). The photovoltaic devices were characterized by J-V curves and electrochemical impedance to obtain their final efficiencies.

\section{Materials and Methods}

All chemicals (reagent grade: Sigma-Aldrich, Dynamics and Vetec) were used as received, without further purification processes. All solutions were prepared with deionized water.

\subsection{Synthesis of titanate nanotubes and nanoribbons}

The titanate nanotubes (NaTiNT) and nanoribbons synthesis performed in this work was based on the method described by Ferreira et al. ${ }^{7,10}$

Typically, the NaTiNT, with chemical composition $\mathrm{Na}_{2}$ ${ }_{x} \mathrm{H}_{\mathrm{x}} \mathrm{Ti}_{3} \mathrm{O}_{7} \cdot \mathrm{nH}_{2} \mathrm{O}(0 \leq \mathrm{x} \leq 2)$, was obtained from $\mathrm{TiO}_{2}$ anatase (Vetec) by hydrothermal method in highly alkaline medium. Anatase powder (1.5 g) was suspended in a concentrated solution of $\mathrm{NaOH}(10 \mathrm{~mol} / \mathrm{L})$ and transferred to an autoclave where it remained for $24 \mathrm{~h}$ at the temperature of $160 \pm 5$ ${ }^{\circ} \mathrm{C}$. Afterwards, the white solid was washed with deionized water until $\mathrm{pH}$ of the supernatant was between 11 and 12 . The titanate nanoribbons, with the same chemical composition, were prepared increasing the temperature of hydrothermal treatment from 160 to $190 \pm 5^{\circ} \mathrm{C}$, keeping the same time ${ }^{10}$.

\subsection{Deposition of the nanostructures via electrophoretic deposition (EPD)}

For the deposition of the nanostructured films, a source of electrophoresis of the Kasvi brand with maximum voltage of 300 Volts and maximum current of $700 \mathrm{~mA}$, was used. Due to the different dispersion characteristics of the materials, the three films formed with the nanostructures of $\mathrm{TiO}_{2}, \mathrm{NaTiNT}$ and Nanoribbons had the following preparation methods:

i) For a suitable dispersion of $\mathrm{TiO}_{2}$ without using any surfactant or additive, in this work, $0.04 \mathrm{~g}$ of this material was dispersed in a solution of $30 \mathrm{~mL}$ of isopropyl alcohol (Dynamic) and $10 \mathrm{~mL}$ of acetone (Dynamic) followed by the addition of $5 \mathrm{~mL}$ of a solution containing $0.18 \mathrm{~g}$ sublimed iodine (Vetec) in $50 \mathrm{~mL}$ of acetone. The solution, then, underwent magnetic stirring (20 min.) and ultrasonic vibration (20 min.) to give $\mathrm{pH}(5 \sim 6)$. The following reaction of iodine and isopropyl alcohol in the solution was reported $^{16}$ :

$\mathrm{CH}_{3}-\mathrm{CO}-\mathrm{CH}_{3}(\mathrm{aq})+2 \mathrm{I}_{2}(\mathrm{aq}) \leftrightharpoons \mathrm{ICH}_{2}-\mathrm{CO}-\mathrm{CH}_{2} \mathrm{I}(\mathrm{aq})+$

$2 \mathrm{H}^{+}(\mathrm{aq})+2 \mathrm{I}^{-}(\mathrm{aq})$
It has also been reported that the presence of $\mathrm{H}^{+}$ions increases the conductivity of the suspension ${ }^{16}$.

ii) For a suitable dispersion of the NaTiNT and Nanoribbons, to each material separately, $15 \mathrm{~mL}$ of ethyl alcohol (Vetec) and $35 \mathrm{~mL}$ of deionized water was used. The solutions were then stirred for $20 \mathrm{~min}$ and ultrasonicated for another $20 \mathrm{~min}$. Finally, $\mathrm{pH}$ was adjusted to $8 \sim 9$ for NaTiNT and to $9 \sim 10$ for the nanoribbon suspensions.

After ultrasonication treatment, the suspensions were put parallel in a container for electrophoresis; for the solution containing the dispersion of $\mathrm{TiO}_{2}$, the commercial FTO (Tin oxide doped with fluorine) glass $\left(\mathrm{SOLEMS}^{\circledR}\right)$ was used as the cathode and commercial platinum substrate as the anode with distance $1.5 \mathrm{~cm}$ in between, during the EPD process. The average electrical resistances of these FTO glass were $50-70 \Omega /$ sq. The EPD was performed at a constant voltage of $80 \mathrm{~V}$ during one minute for each deposition; double layer deposition was used to decrease the cracks in film.

Already for the suspensions containing the NaTiNT and Nanoribbons, the EPD process was performed at a constant voltage of $15 \mathrm{~V}$, during one minute for each deposition; three layer depositions were used to decrease the cracks in the film. For the NaTiNT, three minutes of deposition were used at two layers deposition. In both cases, FTO glass was used as the anode and platinum as the cathode.

After the coating, three films were annealed in air at $450^{\circ}$ $\mathrm{C}$ during $30 \mathrm{~min}$. to enhance the interconnection between the nanostructures. Therefore, in this work, three samples were thermally treated and three others had no heat treatment, in order to verify the performance of these films in the DSSCs.

\subsection{Assembly of the photovoltaic cells}

After the preparation of the films, treated and not treated thermally, it were bathed in dye N719 solubilized in alcohol ethylic with concentration $3 \times 10^{-4} \mathrm{~mol} / \mathrm{L}$, for $24 \mathrm{~h}$. At the following, the FTO/film/dye surface was dried at ambient temperature.

The DSSCs assembly was performed using a commercial transparent platinum counter electrode ${ }^{15}$. The connection of the layers occurred by means of a commercial regenerating electrolyte containing the $\left(\mathrm{I}_{3}^{-} / 3 \mathrm{I}^{-}\right)$redox pair ${ }^{15}$. Finally, the six devices containing films with and without thermal treatment were characterized by $\mathrm{J}-\mathrm{V}$ curves and by electrochemical impedance spectroscopy, which will be shown later.

\subsection{Structural measurements}

X-ray diffraction measurements were made in the NaTiNT, Nanoribbons and $\mathrm{TiO}_{2}$ samples in the powder form by using a XRD diffractometer, model D8 Advanced - Bruker with angular variation $(2 \theta)$ between 5 and $70^{\circ}$, a step size of $0.02^{\circ}$, a step time of $10 \mathrm{~s}$, input and output slots of $0.2 \mathrm{~mm}$, and a current and voltage of $40 \mathrm{~mA}$ and $40 \mathrm{kV}$, respectively, applied in the copper ampoule $(\mathrm{Cu}-\mathrm{K} \alpha, 0.15406 \mathrm{~nm})$. 
Raman spectroscopy was also performed on the NaTiNT, Nanoribbons and $\mathrm{TiO}_{2}$ samples, in the powder form, using a LabRAM HR equipment - Horiba Scientific. The spectra was obtained in backscattering, using as excitation sources the $633 \mathrm{~nm}$ line of a $\mathrm{He}-\mathrm{Ne}$ laser and the $785 \mathrm{~nm}$ line of a diode laser. The Raman spectrum was collected using a 600 $\mathrm{gr} / \mathrm{mm}$ diffraction grating.

\subsection{Morphological measurements}

For the morphological characterization of the films samples NaTiNT, Nanoribbons and $\mathrm{TiO}_{2}$, the films were not covered by conductor film for the scanning electron microscopy (SEM) measurements on a Quanta FEG-450. The measurement conditions were: working distance (WD) of $10.0 \mathrm{~mm}$ and accelerating voltage of $20 \mathrm{kV}$.

\subsection{Optical measurements}

Reflectance measurements were performed on a spectrophotometer Ocean optics USB 2000+ brand in reflection mode. Subsequently, the measurements performed in the reflectance mode were converted to absorbance data using the Kubelka and Munk ${ }^{17}$ method available in the spectrophotometer itself.

\subsection{Electrical measurements}

For all the assembled DSSCs, electric measurements were made by two electrodes potentiostat using 100 $\mathrm{mW} / \mathrm{cm}^{2}$ light source of Led white-neutral. The electrical parameters and current-to-voltage $\left(\mathrm{J}_{\mathrm{SC}}-\mathrm{V}_{\mathrm{OC}}\right)$ density curves, in addition to the parasitic resistances, were obtained based on the circuit model proposed by Vittal at al. ${ }^{18}$ in order to obtain the efficiencies of the cells. All data of the curves $(\mathrm{J}-\mathrm{V})$ are shown in Table 1. Electrochemical impedance spectroscopy (EIS) was used to obtain the load transport resistance associated to the recombination of electrons at the interfaces of the films with the dye and the electrolyte. During the measurements, the cells were under $100 \mathrm{~mW} /$ $\mathrm{cm}^{2}$ of power illumination. The tests were performed under open circuit potential (OCP) with perturbation amplitude of $10 \mathrm{mV}$ and $100 \mathrm{kHz}-1.0 \mathrm{~Hz}$ frequency range. All data of (EIS) are shown in Table 2.

\section{Results and Discussion}

\subsection{X-Ray Diffraction and Raman Spectroscopy}

The structural analysis of the $\mathrm{TiO}_{2}, \mathrm{NaTiNT}$ and Nanoribbon samples was performed on dry powder form, by XRD. Figure $1(\mathrm{~A})$ shows the results, confirming the anatase phase (ICDS 024276) for $\mathrm{TiO}_{2}$ and the formation of titanate nanotubes $\left(\mathrm{Na}_{2} \mathrm{Ti}_{3} \mathrm{O}_{7}\right)$ (ICSD 015463). The XRD pattern of the nanoribbons sample is similar to the titanate phase. The presence of thin peaks for the Nanoribbons is due to the well defined planes in the same direction. Therefore, there is a different pattern for the diffraction of Nanoribbons and Nanotubes.

Figure 1(B) shows the Raman spectra of $\mathrm{TiO}_{2}$, NaTiNT and Nanoribbons. The samples were analyzed on dry powder form. The Raman spectroscopy of the $\mathrm{TiO}_{2}$ anatase phase identified five vibrational modes in 148, 205, 401, 520 and $639 \mathrm{~cm}^{-1}$. Similar results were, also, obtained by different authors $^{19,7,9,10}$.

In a typical spectrum for NaTiNT (Figure 1(B)), there are two intense peaks at 290 and $448 \mathrm{~cm}^{-1}$, and less intense peaks at 388,827 and $917 \mathrm{~cm}^{-1} .{ }^{19,20}$ Bavykin et al. ${ }^{21}$. affirm that the peak at $448 \mathrm{~cm}^{-1}$ is related to Ti-O-Ti vibration modes and the peak at $917 \mathrm{~cm}^{-1}$ is attributed to Ti-O-Na vibrations.

For the nanoribbons, many authors ${ }^{22,7,10,19}$ suggest that the peaks in 141 and $153 \mathrm{~cm}^{-1}$ are associated to the vibrational nature of the anatase phase, the 179 and $195 \mathrm{~cm}^{-1}$ peaks are attributed to the Na-O-Ti mode and the 284 and $300 \mathrm{~cm}^{-1}$ peaks correspond to the Ti-O modes.

\subsection{Structural and morphological analysis of the NaTiNT films, Nanoribbons and $\mathrm{TiO}_{2}$ on FTO}

The SEM images from Figure $2((\mathrm{~A})$ - (F)) show the surface morphology for the films of $\mathrm{TiO}_{2}, \mathrm{NaTiNT}$ and Nanoribbons, with and without thermal treatment at 450 ${ }^{\circ} \mathrm{C}$. From Figure 2 (E and $\mathrm{F}$ ), it is possible to observe the preservation of elongated morphologies from the NaTiNT and Nanoribbons nanostructures, respectively, even after thermal treatment. The thermally treated nanostructures have nanorods and nanoribbons morphology.

Table 1. Cell electrical parameters: (A) $\mathrm{TiO}_{2}$; (A1) $\mathrm{TiO}_{2}-450{ }^{\circ} \mathrm{C}$; (B) NaTiNT; (B1) NaTiNT-450 ${ }^{\circ}$; (C) Nanoribbons and (C1) Nanoribbons $-450{ }^{\circ} \mathrm{C}$.

\begin{tabular}{cccccccc}
\hline $\begin{array}{c}\text { Electrical } \\
\text { parameters/Cells }\end{array}$ & Jsc (mA/cm $\left.{ }^{2}\right)$ & Voc (V) & FF (\%) & Rs & Rsh & $\begin{array}{l}\text { Maximum } \\
\text { Power (W) }\end{array}$ & $\eta(\%)$ \\
\hline (A) & 0.4028 & 0.6274 & 48.5 & $364.7 \Omega$ & $7.7 \mathrm{k} \Omega$ & $1.22 \times 10^{-4}$ & 0.122 \\
(A1) & 0.3310 & 0.6762 & 48.0 & $388.5 \Omega$ & $7.8 \mathrm{k} \Omega$ & $1.07 \times 10^{-4}$ & 0.107 \\
(B) & 0.0012 & 0.1562 & 28.5 & $88.1 \mathrm{k} \Omega$ & $140.6 \mathrm{k} \Omega$ & $5.45 \times 10^{-8}$ & 0.0000547 \\
(B1) & 0.4269 & 0.6298 & 45.9 & $331.5 \Omega$ & $4.5 \mathrm{k} \Omega$ & $1.23 \times 10^{-4}$ & 0.123 \\
(C) & 0.0398 & 0.3027 & 36.4 & $2.6 \mathrm{k} \Omega$ & $12.4 \mathrm{k} \Omega$ & $4.37 \times 10^{-6}$ & 0.0043 \\
(C1) & 0.0765 & 0.5493 & 57.4 & $938.5 \Omega$ & $25.7 \mathrm{k} \Omega$ & $2.41 \times 10^{-5}$ & 0.0241 \\
\hline
\end{tabular}


Table 2. Parameters for the circuit elements of the $\mathrm{TiO}_{2}$ cells (A); $\mathrm{TiO}_{2}-450{ }^{\circ} \mathrm{C}(\mathrm{A} 1)$; NaTiNT (B); NaTiNT-450 ${ }^{\circ} \mathrm{C}$ (B1); Nanoribbons (C) and Nanoribbons- $450^{\circ} \mathrm{C}(\mathrm{C} 1)$.

\begin{tabular}{cccccccc}
\hline Cell & $R_{S}$ & $\mathrm{R} 1$ & \multicolumn{2}{c}{$\mathrm{CPE} 1 \mathrm{Y}_{\mathrm{o}}(\mu \mathrm{Mho}) N$} & $\mathrm{R} 2$ & \multicolumn{2}{c}{$\mathrm{CPE} 2 \mathrm{Y}_{\mathrm{o}}(\mu \mathrm{Mho}) N$} \\
\hline $\mathrm{A}$ & $17.9 \Omega$ & $386.0 \Omega$ & 47.8 & 0.838 & $5.60 \Omega$ & 91.8 & 0.795 \\
$\mathrm{~A} 1$ & $27.2 \Omega$ & $745.0 \Omega$ & 37.1 & 0.758 & $25.6 \Omega$ & 20.8 & 0.858 \\
$\mathrm{~B}$ & $467 \Omega$ & $125.0 \mathrm{k} \Omega$ & 3.65 & 0.850 & $639.0 \Omega$ & 39.1 & 0.507 \\
$\mathrm{~B} 1$ & $81.9 \Omega$ & $1.66 \mathrm{k} \Omega$ & 9.33 & 0.779 & $284.0 \Omega$ & 3.31 & 0.847 \\
$\mathrm{C}$ & $18.4 \Omega$ & $1.16 \Omega$ & $13.1 \mu \mathrm{F}$ & 1.00 & $3.67 \mathrm{k} \Omega$ & 49.7 & 0.878 \\
$\mathrm{C} 1$ & $74.4 \Omega$ & $110.0 \Omega$ & 2.18 & 0.920 & $458.0 \Omega$ & 45.0 & 0.631 \\
\hline
\end{tabular}

(A)

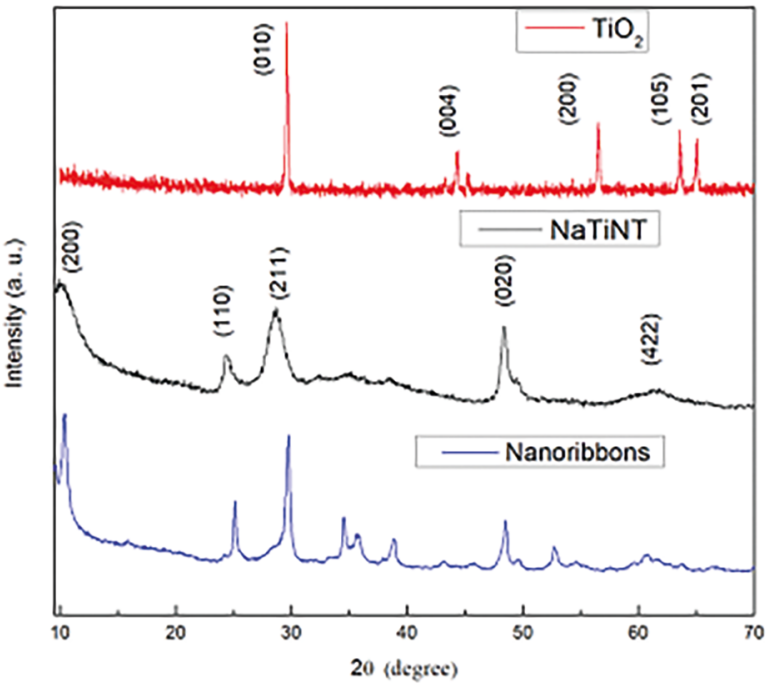

(B)

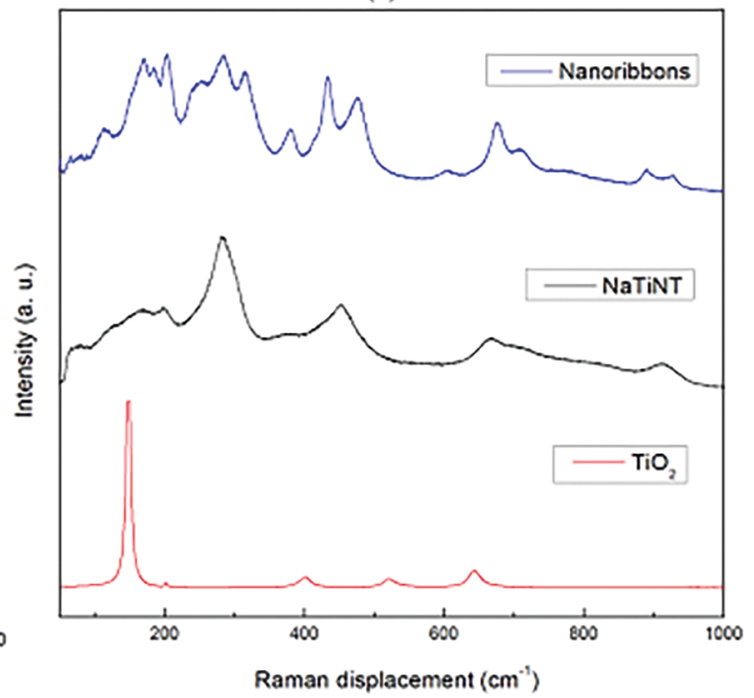

Figure 1. (A) XRD patterns of the $\mathrm{TiO}_{2}$, NaTiNT and Nanoribbons powders; (B) Raman spectra of the NaTiNT, Nanoribbons and TiO 2 powders samples.

The NaTiNT situation demonstrated the collapse of the tube's walls with evaporation of the adsorbed water, turning to nanorods after thermic treatment. Figure 2 (D) shows non-significant changes in the $\mathrm{TiO}_{2}$ film, after thermic treatment. However, there was major film compaction and possible pores reduction.

\subsection{Optical characterization of the $\mathrm{TiO}_{2}, \mathrm{NaTiNT}$ and Nanoribbons films before and after thermal treatment}

The spectrophotometry measurements were performed on the films as deposited. The images from Figure 3 ((A) (D)) show the absorbance of the investigated films before and after thermal treatment.

From these images, the spectrums shift, red curve, occurs near the visible region, after thermal treatment, except for the $\mathrm{TiO}_{2}$ film. The shift in the absorption spectrum for the near the visible region is linked to the reduction of the band gap energy of the films. It is possible to link these shifts in the absorption spectrum to the structural changes which occur when heating the nanostructures ${ }^{23,24}$.
The structural changes from Nanotubes to Nanorods in the NaTiNT films after thermal treatment were responsible for a higher absorption, for these materials, in the spectrum close to the visible. The same effect did not happen with the $\mathrm{TiO}_{2}$ film, once there was no significative structural changes after the heat treatment, as it is possible to observe from the SEM images. Figure 3 (D) shows the superposition of the spectrums before and after the thermal treatment. From figure 3 (D) it is observed that the thermal treated NaTiNT film absorbs light very near the regions absorbed by $\mathrm{TiO}_{2}$. This occurs due to the proximity in the band gap energy.

\subsection{Photoelectrochemical characterization of the cells built with films of $\mathrm{TiO}_{2}$, NaTiNT and Nanoribbons before and after thermal treatment}

The films deposited by electrophoresis were previously prepared to be used as working electrodes of dye sensitized solar cells. The assembly of these cells happened as described in section 2.3 and the cells were characterized according to the conditions presented in the section 2.7. The images from 

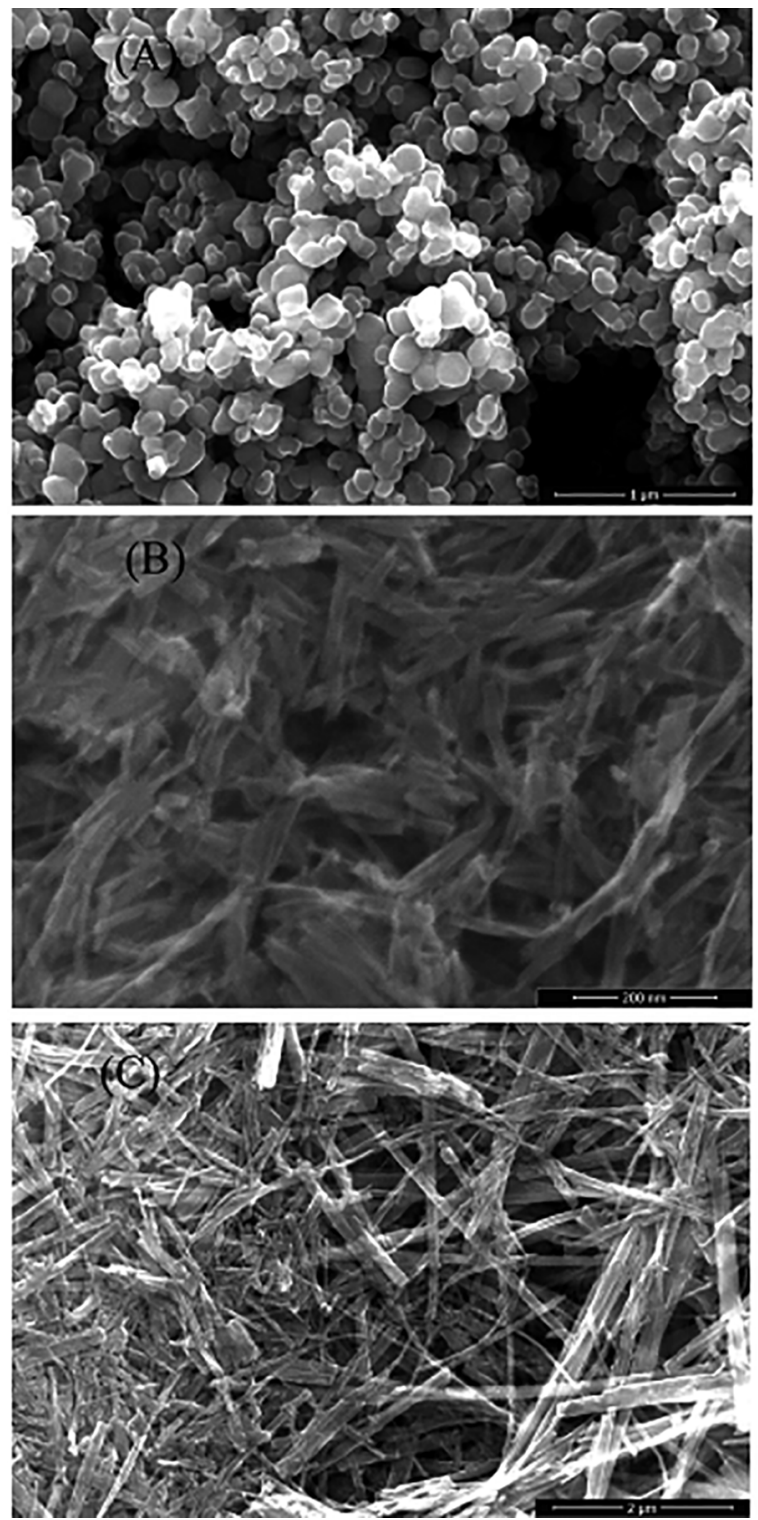

Figure 2. SEM micrograph of the films samples before the heat treatment: (A) $\mathrm{TiO}_{2}$; (B) NaTiNT; (C) Nanoribbons and (D) $\mathrm{TiO}_{2}$; (E) NaTiNT; (F) Nanoribbons after the heat treatment.

Figure 4 ((A)-(C1)) presented current density-voltage curves and the potential of the cells with nanostructures of films before and after thermal treatment. Table 1 shows the mainly electrical parameters extracted from the cells (J-V) curves.

From Table 1 data, it is verifiable an increase of the cells efficiency $(\eta)$ after thermal treatment, except for the cell with $\mathrm{TiO}_{2}$. It is noticed expressive increase of the current and tension parameters for the cells with NaTiNT and Nanoribbons structures, after thermal treatment. The enhancement of the series resistance (Rs) is responsible for the decrease on the current extracted from the cells. Yet, the fill factor (FF) decrease is associated to the Rs increase and to the reduction of the shunt resistance (Rsh), which contributes to the decrease in the cells efficiency. These
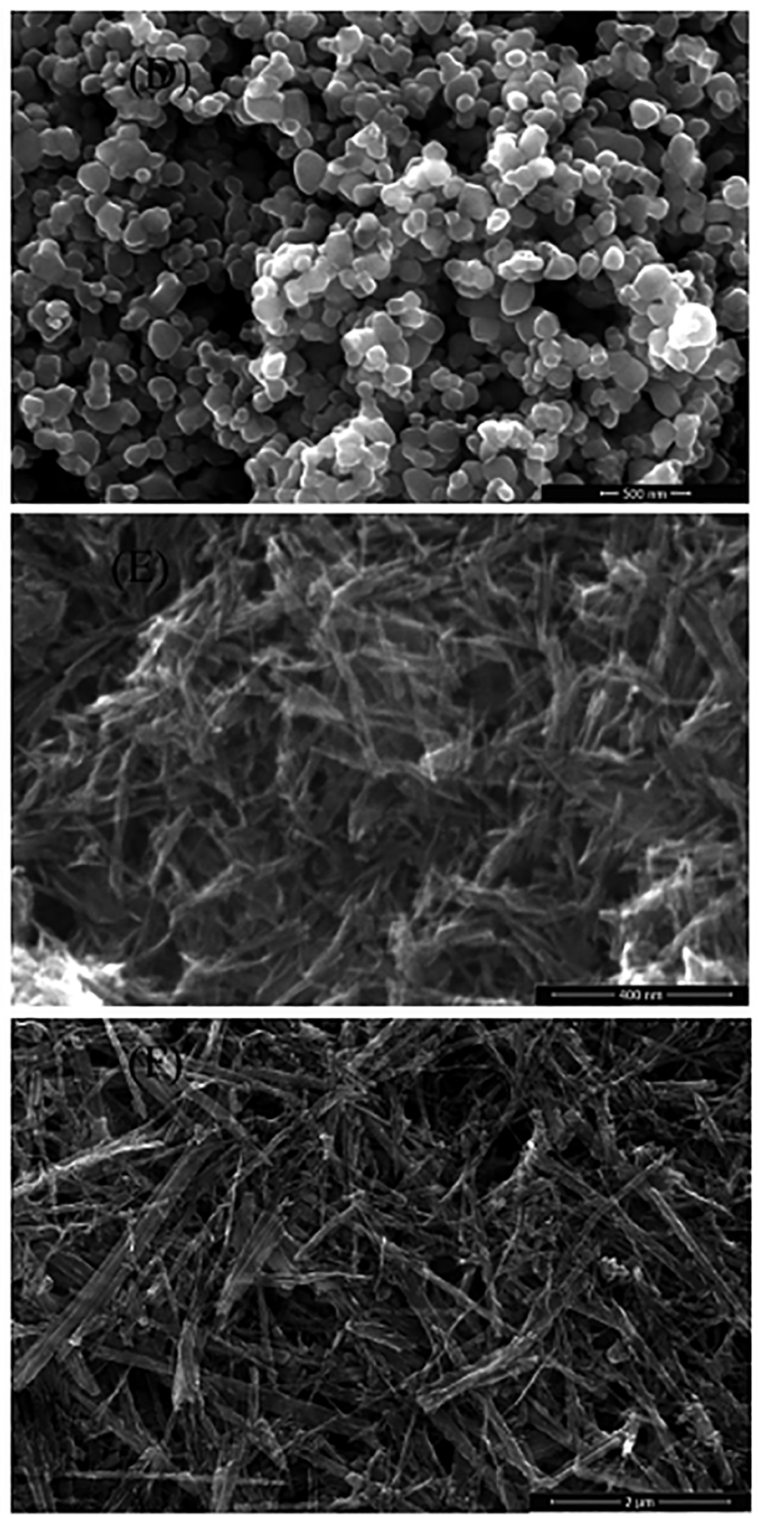

parameters became favorable for the TiNTs after the films thermal treatment.

The efficiency of the cell with $\mathrm{TiO}_{2}$ slightly reduced after thermal treatment. This is due, possibly, to a higher compaction of the film, which reduced the pores and made the dye adsorption more difficult. For this cell, it is possible to see, from the Table 1, an increase in the Rs and reduction of Rsh and FF, which decreased the cell performance.

The electrochemical impedance spectroscopy (EIS) analysis is an effective technique for the characterization of electrochemical systems. In the DSSC field, it is one of the most useful experimental techniques, as it permits a simultaneous characterization of the different processes taking place on the cell ${ }^{25,26}$. A key attractive feature is its 
(A)

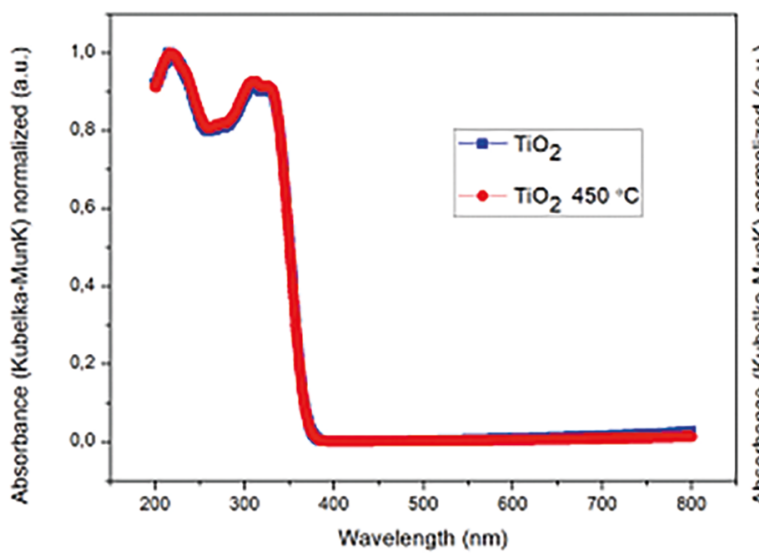

(B)

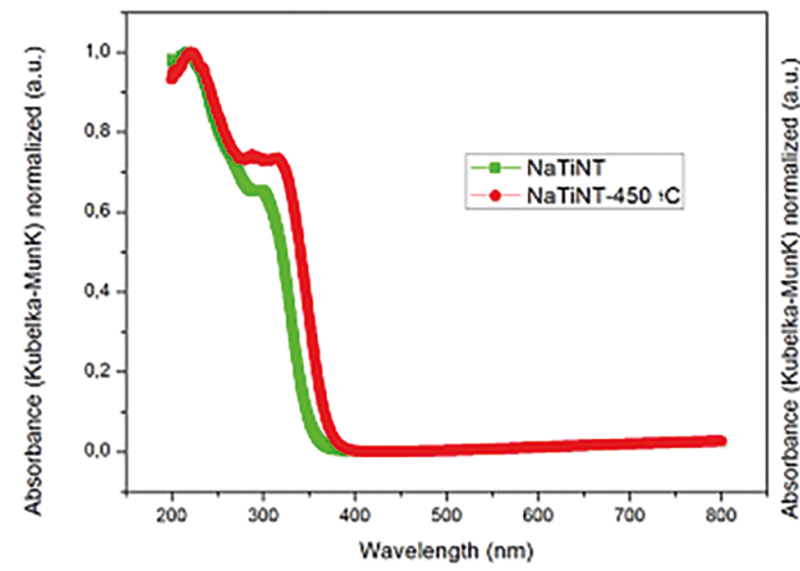

(C)

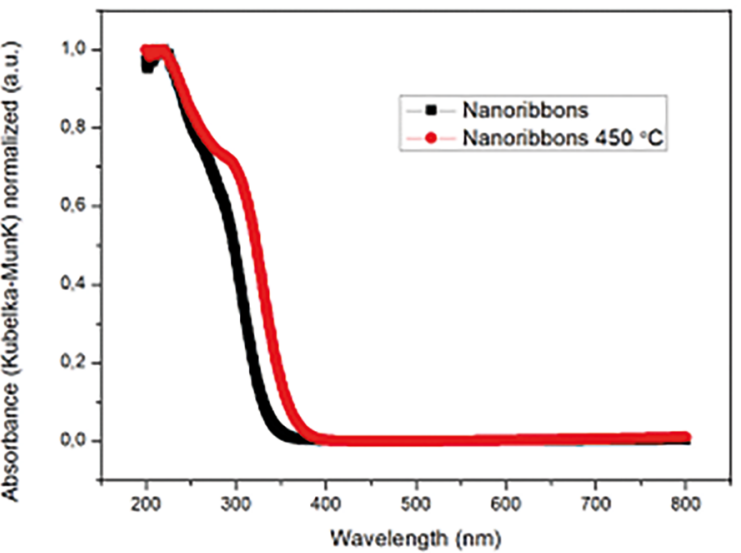

(D)

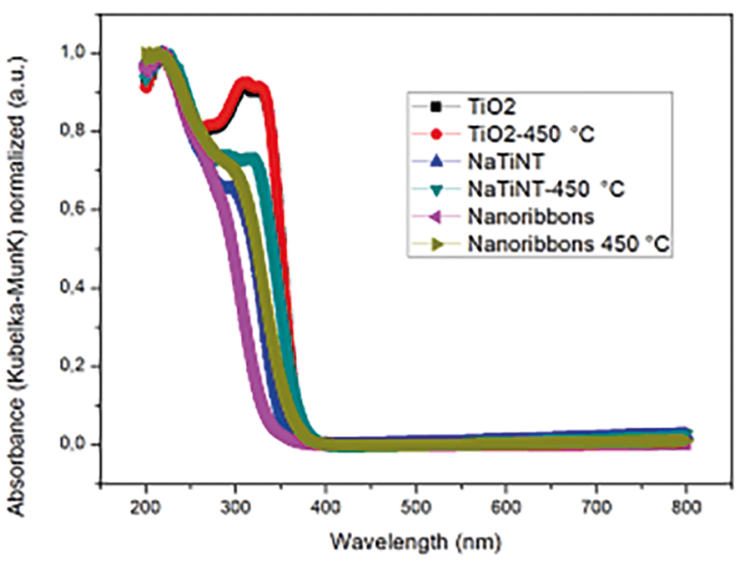

Figure 3. Absorbance of the films: (A) $\mathrm{TiO}_{2}$; (B) NaTiNT; (C) Nanoribbons and (D) overlap of the spectrums before and after the heat treatment.

application on full solar cell devices and the indication of the main limitations of the cell photoelectrical performance.

The EIS was used to investigate the resistance to the transport and transfer of charges related with the electrons recombination in the semiconductor/dye/electrolyte interfaces. The cells with films before and after thermal treatment were analyzed. The conditions were described in section 2.7. Figures 5 (A,A1), 6 (B,B1) and $7(\mathrm{C}, \mathrm{C} 1)$ show the Nyquist diagrams of the cells obtained experimentally and adjusted to the spectrums calculated through equivalent circuits, shown, also, in the figures.

In the impedance figures, the intersection in the real axes in high frequency is the ohmic series resistance $\left(R_{S}\right)$, which is, also, presented in the Figures 5,6 and 7. The constant phase elements (CPE1 and CPE2) are related to the first and second curve, respectively. The $\mathrm{CPE}$ is frequently used as a substitute to the capacitor element to adjust the impedance behavior related to the double electrical layer, when it does not act as an ideal capacitor. The CPE is mathematically defined as:

$$
Z_{C P E}=\frac{1}{\mathrm{Y}_{0}}(j \omega)^{N}
$$

Where, $\mathrm{Y}_{0}$ is $\mathrm{CPE}$ admittance and $\mathrm{N}$ can assume values between 0 and 1 (CPE is a resistor for $\mathrm{N}=0$ or an ideal capacitor for $\mathrm{N}=1)^{27}$.

The obtained Nyquist diagrams show two semicircles, one with lower circumference situated in regions of higher frequency, which is related to the charge transfer in the interface counterelectrode/electrolyte (R1) and another with a larger circumference situated in lower frequency regions. This last one is related to the charge transfer in the interface semiconductor/dye/electrolyte (R2) ${ }^{28}$.

Figures 8 ((A), (B), (C)) show the overlapping Nyquist diagrams, where it is possible to observe the diameters reduction of the semicircles related to the cells with the NaTiNT and Nanoribbons films after thermal treatment. Those reductions, especially of the second curve related to the $\mathrm{R} 2$ in the circuit, are associated to an improved electrons transport in the semiconductor film ${ }^{27,28}$. Besides, it is possible to observe in the samples with $\mathrm{TiO}_{2}$, after thermal treatment, an increase in the diameters of the curves related to the R2, which implies a reduction of the electrons transport for this material. In addition, Figure 8 (B) shows the shift, into the real axes, to a lower impedance value, $R s$, after thermal 


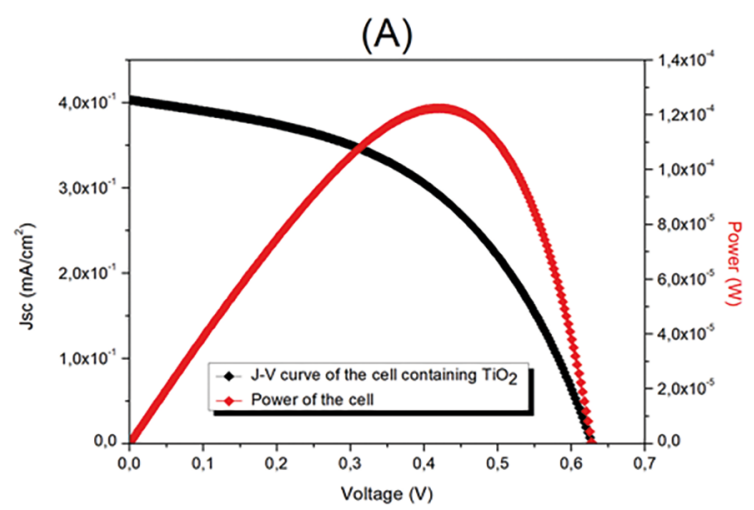

(B)

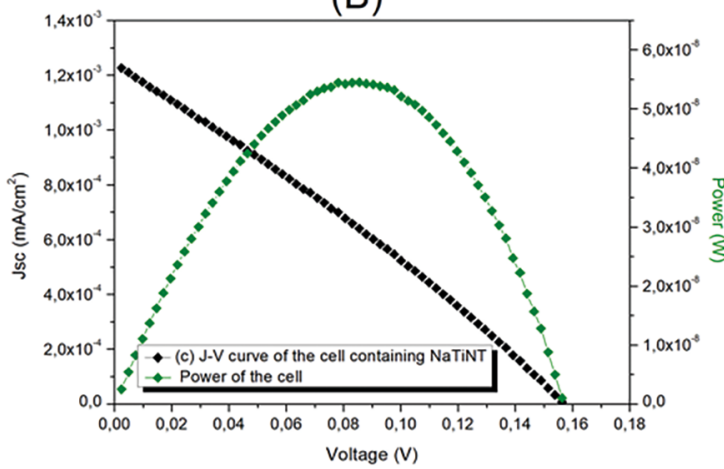

(C)

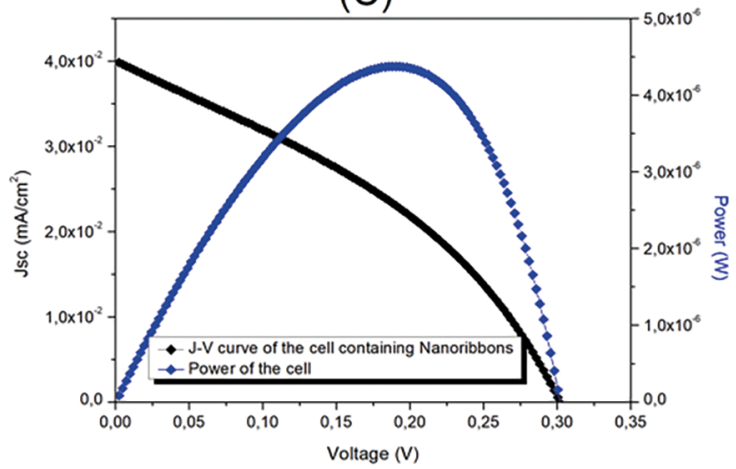

(A1)

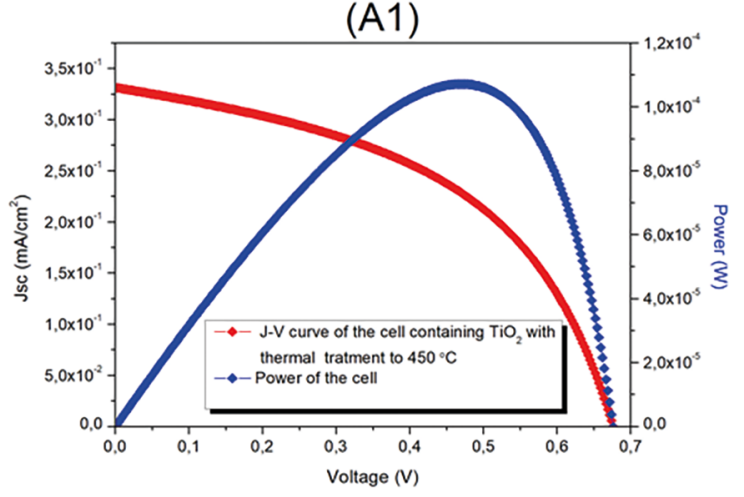

(B1)

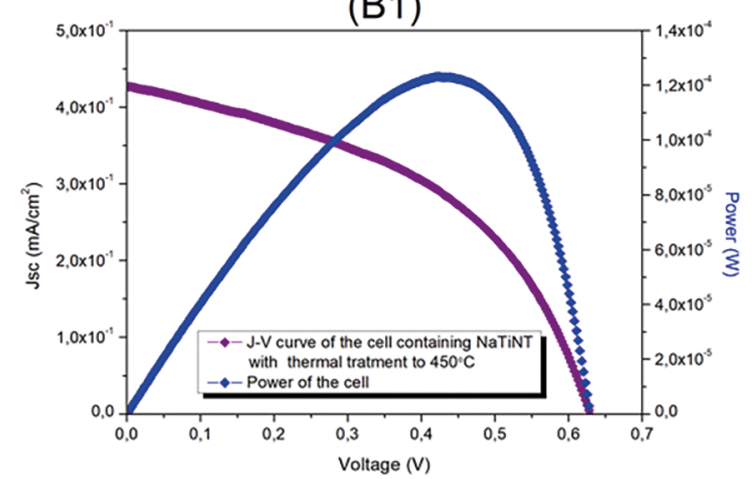

(C1)

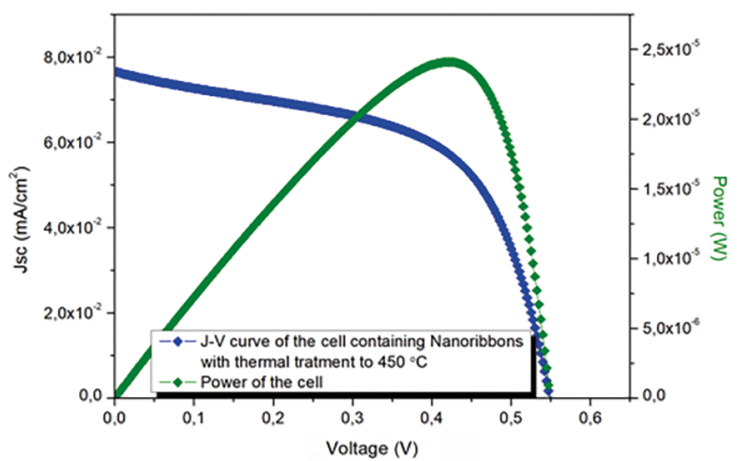

Figure 4. J-V Curves: (A) $\mathrm{TiO}_{2}$; (A1) $\mathrm{TiO}_{2}-450{ }^{\circ} \mathrm{C}$; (B) NaTiNT; (B1) NaTiNT-450 ${ }^{\circ} \mathrm{C}$; (C) Nanoribbons and (C1) Nanoribbons-450 ${ }^{\circ} \mathrm{C}$.

treatment. This series resistance is related to the sum of all dissipative resistances, which may be considered in series on the circuit $^{29,30}$. For the NaTiNT nanostructures, after thermal treatment, the cell series resistance is reduced considerably. This reduction can be due to the extinction of dissipative impurities adsorbed on the nanostructures, for example $\mathrm{OH}^{-}$groups and oxygen vacancies, and to the structural changes, which shift the circuit to lower impedance values. However, for the remain cells, the $R s$ increased slightly, which suggests the appearance of dissipative elements, after thermal treatment. Structural changes, on cells from Figures $\mathrm{A}$ and $\mathrm{C}$, also may have increased the series resistance. Therefore, the impedance values also depend on the nature and structure of the semiconductor ${ }^{29,30}$.
Observing the table 2 data, it is noticeable the decrease in the resistances $\mathrm{R} s, \mathrm{R}_{1}$ and $\mathrm{R}_{2}$ for the cells with the titanate nanostructures NaTiNT and Nanoribbons, after thermal treatment. These reductions in the resistance to the transport and transfer of charges improve the photocurrent generated by the cells. Such growth is due, mainly, to the decrease in the electrons recombination in the interface semiconductor/electrolyte ${ }^{31}$. The resistances decrease maybe happened, also, due to the elimination of defects produced by the $\mathrm{OH}^{-}$groups in the titanate films after thermal treatment. The presence of adsorbed groups justifies the inductive element in the circuit related to these materials ${ }^{32}$.

Therefore, all the previously mentioned facts contributed to an increase of the efficiency of the cells with the titanates, 
(A)

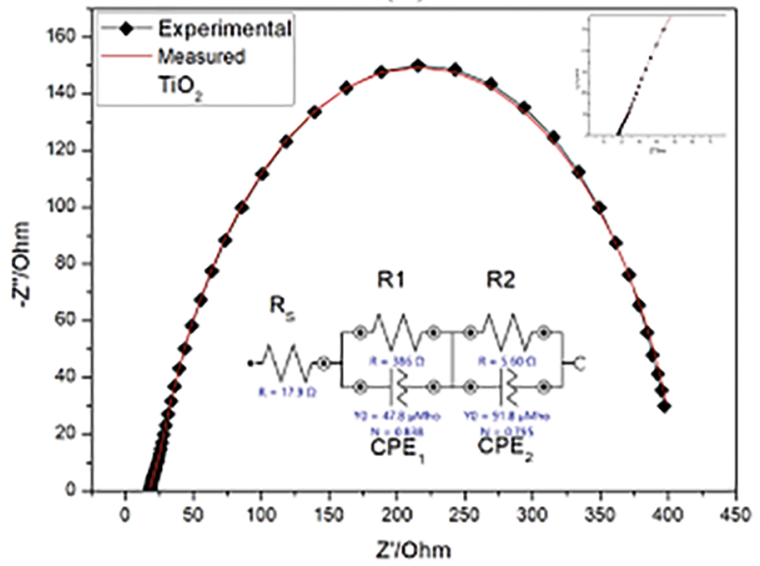

(A1)

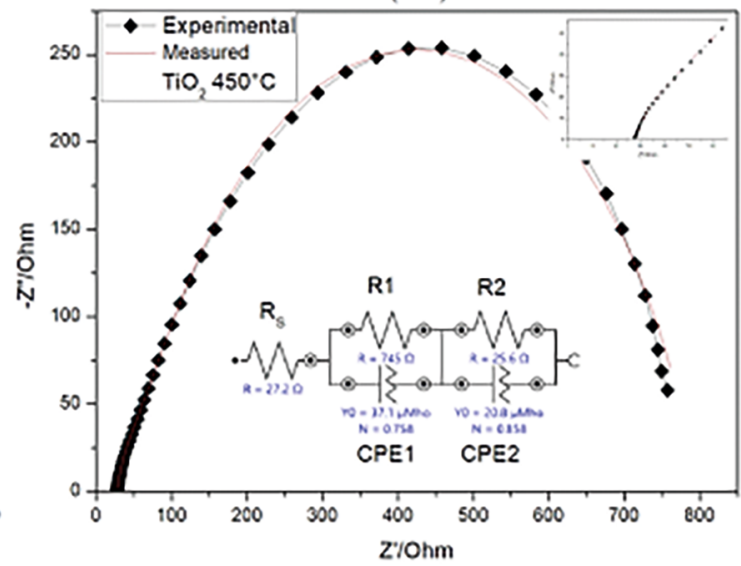

Figure 5. Nyquist diagrams of the cells with (A) $\mathrm{TiO}_{2}$ and (A1) $\mathrm{TiO}_{2}-450{ }^{\circ} \mathrm{C}$.

(B)

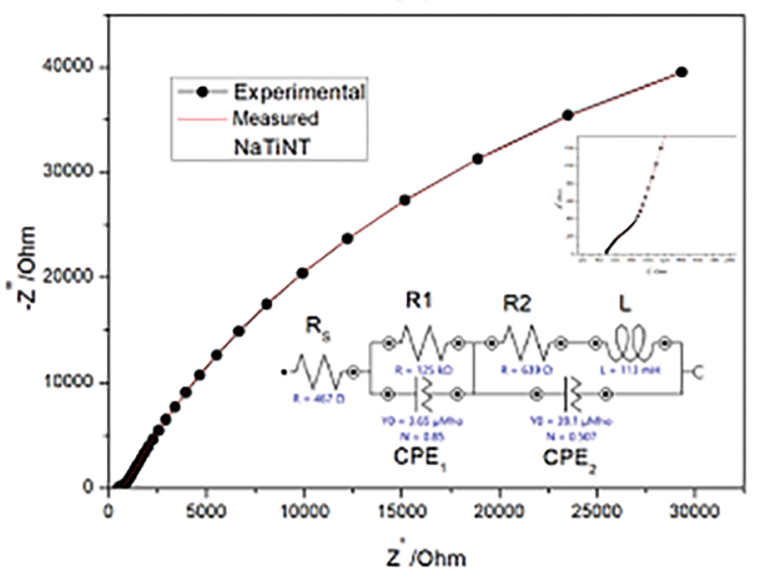

(BI)

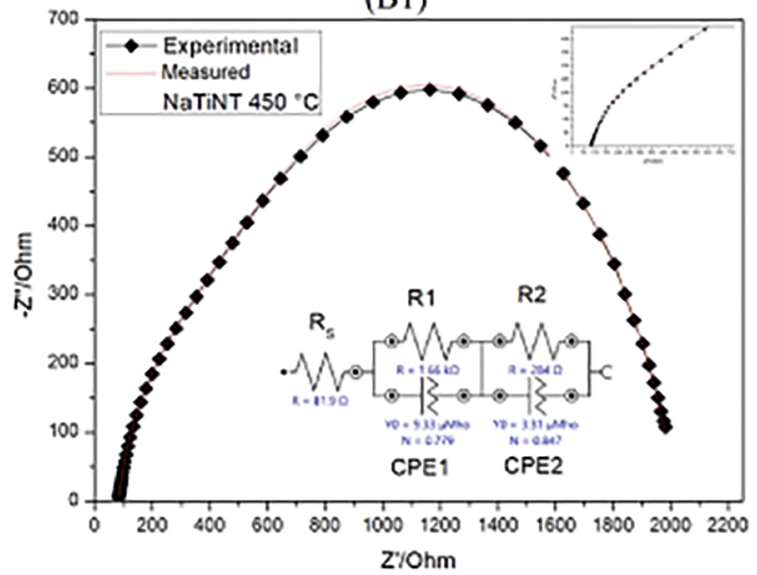

Figure 6. Nyquist diagrams of the cells with (B) NaTiNT and (B1) NaTiNT-450 ${ }^{\circ} \mathrm{C}$.

(C)

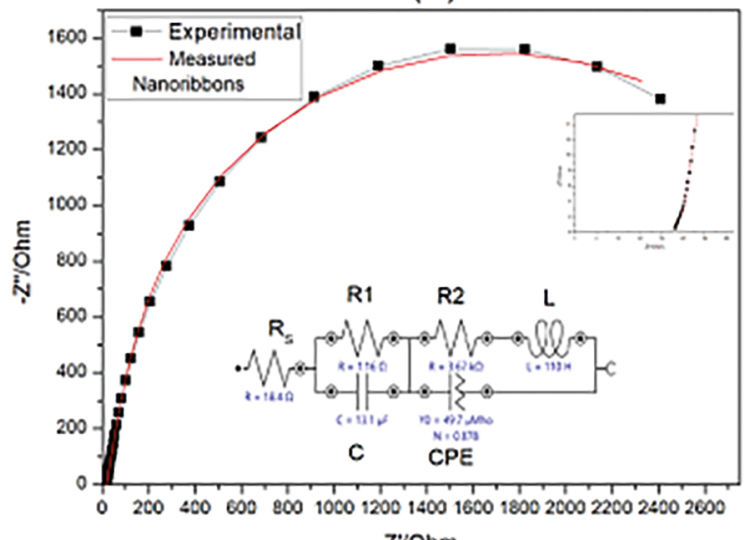

(C1)

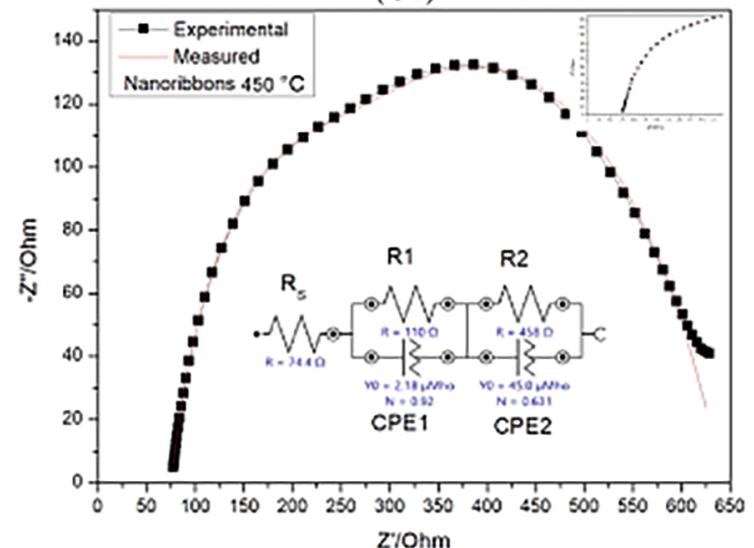

Figure 7. Nyquist diagrams of the cells with (C) Nanoribbons and (C1) Nanoribbons- $450{ }^{\circ} \mathrm{C}$. 
(A)

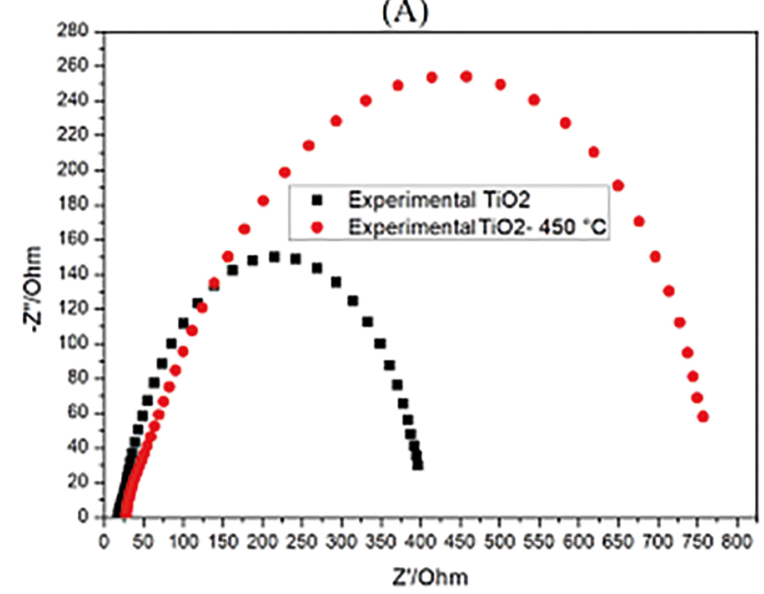

(B)

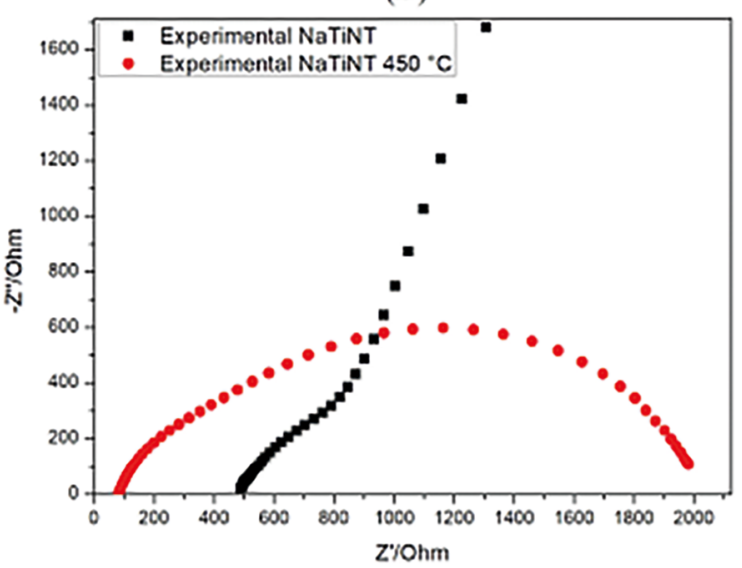

(C)

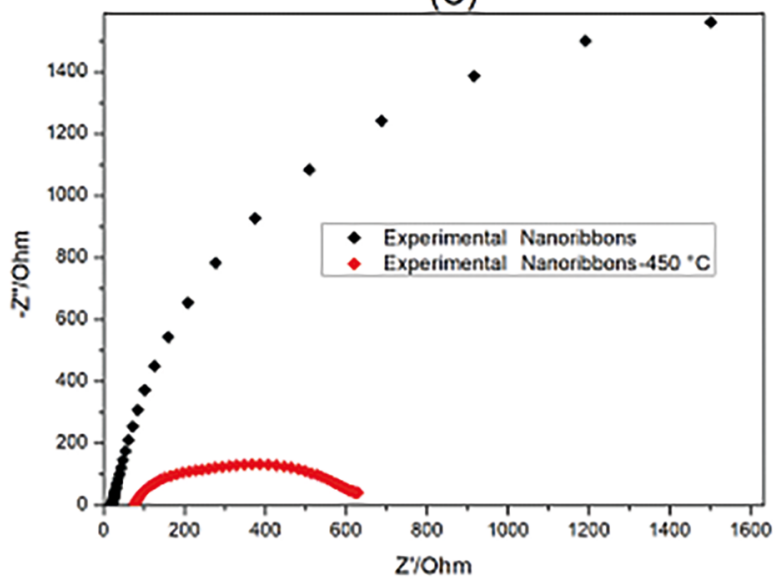

Figure 8. Superpositioned Nyquist diagrams of the cells: A) $\mathrm{TiO}_{2} / \mathrm{TiO}_{2}-450{ }^{\circ} \mathrm{C}$; B) NaTiNT/NaTiNT-450 ${ }^{\circ} \mathrm{C}$ and C) Nanoribbons/ Nanoribbons $-450{ }^{\circ} \mathrm{C}$.

after thermal treatment. Yet, for the cell with the $\mathrm{TiO}_{2}$, there was a slight increase of the resistances associated to the charge transfer. As already mentioned, this increase maybe happened due to the pores reduction in the $\mathrm{TiO}_{2}$ film, after thermal treatment, which caused lower dye adsorption. For this cell, the efficiency slightly decreased due to the reduction of the charges transfer and electrons transport.

\section{Conclusion}

The investigated nanostructures of $\mathrm{TiO}_{2}, \mathrm{NaTiNT}$ and Nanoribbons deposited successfully on FTO, through the electrophoresis technique. The shift on the absorption spectrums of the films to the regions near the visible, after the thermic treatment, became noticeable for the NaTiNT and Nanoribbons nanostructures, probably due to the structural changes, which happened after the collapse of these nanostructures. The results of the cells J-V curves demonstrated that the cell with the NaTiNT film, after thermal treatment, presented improved evolution of efficiency. This evolution was due to the reduction of the cell parasitic resistances. The impedance analysis for the NaTiNT nanostructures showed a decrease in the resistance to the transfer and transport of charges. This decrease is associated, mainly, to the evaporation of the $\mathrm{OH}^{-}$group, oxygen vacancies responsible for the diffusion of $\mathrm{H}^{+}$ions and production of currents in opposition to the current photogenerated by the cell. Finally, the preliminary studies demonstrated the capacity of these materials to contribute, in the future, to the development of high efficiency photovoltaic devices.

\section{Acknowledgments}

The authors are grateful to Central Analytical UFC/ CT-INFRA/MCTI-SISNANO/Pro-Equipamentos CAPES for providing the scanning electron microscopes. OPF acknowledge support from CAPES-PROCAD 2013 Grant 183995. 


\section{References}

1. Kasuga T, Hiramatsu M, Hoson A, Sekino T, Niihara K. Formation of Titanium Oxide Nanotube. Langmuir. 1998;14(12):31603163 .

2. Zwilling V, Darque-Ceretti E, Boutry-Forveille A, David D, Perrin MY, Aucouturier M. Structure and physicochemistry of anodic oxide films on titanium and TA6V alloy. Surface and Interface Analysis. 1999;27(7):629-637.

3. Kasuga T, Hiramatsu M, Hoson A, Sekino T, Niihara K. Titania Nanotubes Prepared by Chemical Processing. Advanced Materials. 1999;11(15):1307-1311.

4. Ou HH, Lo SL. Review of titania nanotubes synthesized via the hydrothermal treatment: Fabrication, modification, and application. Separation and Purification Technology. 2007;58(1):179-191.

5. Hoyer P. Formation of Titanium Dioxide Nanotube Array. Langmuir. 1996;12(6):1411-1413.

6. Zhao L, Yu J, Fan J, Zhai P, Wang S. Dye-sensitized solar cells based on ordered titanate nanotube films fabricated by electrophoretic deposition method. Electrochemistry Communications. 2009;11(10):2052-2055.

7. Ferreira OP, Souza Filho AG, Mendes Filho J, Alves OL. Unveiling the structure and composition of titanium oxide nanotubes through ion exchange chemical reactions and thermal decomposition processes. Journal of the Brazilian Chemical Society. 2006;17(2):393-402.

8. Bavykin DV, Walsh FC. Elongated Titanate Nanostructures and Their Applications. European Journal of Inorganic Chemistry. 2009;2009(8):977-997.

9. Morgado E Jr, Marinkovic BA, Jardim PM, de Abreu MAS, Rizzo FC. Characterization and thermal stability of cobaltmodified 1-D nanostructured trititanates. Journal of Solid State Chemistry. 2009;182(1):172-181.

10. Viana BC, Ferreira OP, Souza Filho AG, Mendes Filho J, Alves OL. Structural, morphological and vibrational properties of titanate nanotubes and nanoribbons. Journal of the Brazilian Chemical Society. 2009;20(1):167-175.

11. Adachi M, Murata Y, Okada I, Yoshikawa S. Formation of titania nanotubes and application for dye-sensitized solar cells. Journal of the Electrochemical Society. 2003;150(8):G488-G493.

12. Agnaldo JS, Bastos JBV, Cressoni JC, Viswanathan GM. Células solares de $\mathrm{TiO}_{2}$ sensibilizado por corante. Revista Brasileira de Ensino de Física. 2006;28(1):77-84.

13. Falla PH, Dias MOG, Vieira H, Junior RSP, Silva LHX, Nogueira PHO. Optimization the efficiency Photovoltaic Solar Cells using synthesized $\mathrm{TiO} 2$ semiconductor nanomaterials and functionalized Carbon Nanotubes. Faculdade do Gama-FGA/ Universidade do Brasília-UnB-Brazil. Energy Procedia. 2014: 57: $1860-1867$.

14. Roy P, Berger S, Schmuki P. $\mathrm{TiO}_{2}$ Nanotubes: Synthesis and Applications. Angewandte Chemie International Edition. 2011;50(13):2904-2939.
15. Solaronix. Available from: $<\mathrm{http}: / / \mathrm{www}$.solaronix.com $>$. Access in: $12 / 7 / 2017$.

16. Besra L, Liu M. A review on fundamentals and applications of electrophoretic deposition (EPD). Progress in Materials Science. 2007;52(1):1-61

17. Thorne A, Kruth A, Tunstall D, Irvine JTS, Zhou W. Formation, Structure, and Stability of Titanate Nanotubes and Their Proton Conductivity. Journal of Physical Chemistry B. 2005;109(12):54395444.

18. Vittal R, Ho KC. Zinc oxide based dye-sensitized solar cells: A review. Renewable and Sustainable Energy Reviews. 2017;70:920-935.

19. Dresselhaus MS, Lin YM, Rabin O, Jorio A, Souza FAG, Pimenta MA, et al. Nanowires and nanotubes. Materials Science and Engineering: C. 2003;23(1-2):129-140.

20. Viana BC, Ferreira OP, Souza Filho AG, Hidalgo AA, Mendes Filho J, Alves OL. Alkali metal intercalated titanate nanotubes: A vibrational spectroscopy study. Vibrational Spectroscopy. 2011;55(2):183-187.

21. Bavykin DV, Friedrich JM, Walsh FC. Protonated Titanates and TiO2 Nanostructured Materials: Synthesis, Properties, and Applications. Advanced Materials. 2006;18(21):2807-2824. DOI: 10.1002/adma.200502696

22. Abed GM, Alsammarraie AMA, Al-Abdaly BI. Cr Gd co-doped $\mathrm{TiO}_{2}$ Nanoribbons as Photoanode in Making Dye Sensitized Solar Cell. Nanoscience and Nanometrology. 2017;3(1):27-33.

23. Singh AP, Kodan N, Mehta BR. Enhancing the photoelectrochemical properties of titanium dioxide by thermal treatment in oxygen deficient environment. Applied Surface Science. 2016;372:6369.

24. Gu X, Chen F, Zhao B, Zhang J. Photocatalytic reactivity of Ce-intercalated layered titanate prepared with a hybrid method based on ion-exchange and thermal treatment. Superlattices and Microstructures. 2011;50(2):107-118.

25. Juozapavicius M, Kaucikas M, van Thor JJ, O'Regan BC. Observation of Multiexponential Pico- to Subnanosecond Electron Injection in Optimized Dye-Sensitized Solar Cells with VisiblePump Mid-Infrared-Probe Transient Absorption Spectroscopy. Journal of Physical Chemistry C. 2012;117(1):116-123.

26. Juozapavicius M, Kaucikas M, Dimitrov SD, Barnes PRF, van Thor JJ, O'Regan BC. Evidence for "Slow" Electron Injection in Commercially Relevant Dye-Sensitized Solar Cells by visNIR and IR Pump-Probe Spectroscopy. Journal of Physical Chemistry C. 2013;117(48):25317-25324.

27. El-Mahdy GA, Atta AM, Al-Lohedan HA. Water Soluble Nonionic Rosin Surfactants As Corrosion Inhibitor of Carbon Steel in $1 \mathrm{M} \mathrm{HCl}$. International Journal of Electrochemical Science. 2013;8:5052-5066.

28. Wang Q, Moser JE, Grätzel M. Electrochemical Impedance Spectroscopic Analysis of Dye-Sensitized Solar Cells. Journal of Physical Chemistry B. 2005;109(31):14945-14953. 
29. Fabregat-Santiago F, Bisquert J, Palomares E, Otero L, Kuang D, Zakeeruddin SM, et al. Correlation between Photovoltaic Performance and Impedance Spectroscopy of Dye-Sensitized Solar Cells Based on Ionic Liquids. Journal of Physical Chemistry C. 2007;111(17):6550-6560.

30. Idígoras León JA. Photoelectrochemistry of Nanocrystalline Semiconductor Metal Oxides in contact to Liquid Electrolytes: Photocatalytic and Photovoltaic Applications. [Thesis]. Seville: University Pablo de Olavide; 2015.
31. Tripathi B, Yadav P, Kumar M. Charge transfer and recombination kinetics in dye-sensitized solar cell using static and dynamic electrical characterization techniques. Solar Energy. 2014;108:107116.

32. Bisquert J, Fabregat-Santiago F. Impedance Spectrocopy: A General Introduction and Application to Dye-Sensitized Solar Cells. In: Kalyanasundaram K, ed. Dye-sensitized Solar Cells. New York: EPFL Press; 2010. p. 457-554. 